\title{
Conditioned reinforcement strength in rats as a function of pattern of reinforcement ${ }^{1}$
}

DONALD F. MCCAUSLAND, University of Louisville, Louisville, Ky. 40208

One group of rats in each experiment experienced a $90 \%$ transition probability from nonreinforcement to reinforcement. This resulted in short runs of nonreinforced and reinforced stimulus presentations. The other group in each experiment experienced a 10\% transition probability. This resulted in long runs of nonreinforced and reinforced stimulus presentations. Latencies in both groups were significantly shorter on trials with a 90\% reinforcement probability than on trials with a $10 \%$ reinforcement probability. The extinction data indicated that the stimulus had become a conditioned reinforcer for both groups. However, the results of both experiments revealed that the pattern of reinforcement had no differential effect on conditioned-reinforcement strength.

Parameters that have been found to influence the rate of acquisition and the strength of a conditioned response similarly influence the rate of acquisition and the strength of a conditioned reinforcer (Kimble, 1961). Recently, a number of investigators have studied the effects of the pattern of reinforcement on the strength of a conditioned response and have obtained mixed findings. Experiments in this area have been concerned essentially with determining which variables within patterns of reinforcement are responsible for the increased resistance to extinction following partial primary reinforcement (the PRE effect). Lawrence \& Festinger (1962) suggested that the PRE was a function of the number of nonreinforced trials during acquisition and used dissonance theory to account for their results. Capaldi (1964), Capaldi \& Stanley (1965), and Gonzalez \& Bitterman (1964) suggested that the average length of runs of consecutive nonreinforced trials ( $\mathrm{N}$-length) was the crucial factor in determining the extent of the PRE. Their results are compatible with the discrimination hypothesis (Mowrer \& Jones, 1945). Koteskey \& Stettner (1968) observed that the number of nonreinforcementreinforcement (N-R) transitions was a confounded variable in the above studies, and their results, as well as those of Spivey \& Hess (1968) and Spivey, Hess, \& Black (1968), suggest that the number of N-R transitions is the critical factor in determining the extent of the PRE. This hypothesis is compatible with frustration theory (Amsel, 1958). Koteskey (1969), however, was unable to replicate the findings of the earlier study. The results of the above studies indicate that the pattern of reinforcement does have an effect on resistance to extinction, although it is still unclear as to what variable is responsible for the effect. The purpose of the present study was to investigate the effect of the pattern of reinforcement on 'conditioned-reinforcement strength. The similarities between conditioned responses and conditioned reinforcers discussed above suggested this line of inquiry.

\section{EXPERIMENT 1} Subjects

Sixteen naive male Sprague-Dawley albino rats, 100-120 days old, were fed $10 \mathrm{~g}$ of Purina Lab Chow per day beginning 10 days prior to the initiation of training. Water was continuously available.

\section{Apparatus}

Two commercially manufactured operant-conditioning chambers, each equipped with a .045-g Noyes pellet dispenser, were controlled by programming devices located in an adjacent room. The stimulus was a $1-\mathrm{sec}$ presentation of the houselight.

\section{Procedure}

On Day 1, the Ss were magazine trained and, on Day 2, were shaped to barpress and received 150 pellets on a CRF schedule. On the 3rd day, the Ss were divided randomly into two equal groups $(\mathrm{N}=8)$ and given 100 free presentations (response levers removed) of the stimulus on Days 3, 4, and 5. The stimulus was programmed on a variable schedule that averaged one presentation every 60 sec. The stimulus-reinforcement pattern for Group HT-SR was as follows: $10 \%$ of the stimulus presentations following a reinforced presentation were reinforced, and $10 \%$ of the stimulus presentations following a nonreinforced presentation were nonreinforced. Thus, this group experienced a high number of $\mathrm{N}-\mathrm{R}$ transitions between short runs of nonreinforced and reinforced sequences. The corresponding percentages in Group LT-LR were $90 \%$ and $90 \%$. Thus, this group experienced a low number of $\mathrm{N}-\mathrm{R}$ transitions between long runs of nonreinforced and reinforced sequences. Approximately $50 \%$ of the stimulus presentations for each group were followed by reinforcement. On Day 6, the response levers were again available, and the Ss were extinguished during a .5 -h session in which each response produced the stimulus but not reinforcement. The number of responses emitted during extinction was recorded at 5-min intervals.

\section{Results and Discussion}

Group HT-SR received an average of 44.8 N-R transitions per day, each following an N-length that averaged 1.1 nonreinforcements. The corresponding averages for Group LT-LR were 5.2 and 9.5. In each case, the obtained result was quite close to the expected result. Group HT-SR and Group LT-LR emitted an average of 78.8 and 100.0 extinction responses, respectively $(\mathrm{F}<1.0$, $\mathrm{df}=1 / 14)$. The number of extinction responses emitted during each successive 5 -min interval decreased $(F=9.17$, $\mathrm{df}=5 / 70, p<.001)$. The Groups by Extinction Periods interaction was not significant $(F<1.0, d f=5 / 70)$. Thus, the results indicated that the pattern of stimulus-reinforcement pairings had no effect on conditioned reinforcement strength.

\section{EXPERIMENT 2}

In view of the negative results obtained in Experiment 1, Experiment 2 was conducted with a within-Ss design that allowed a more rigorous control of error variance. In addition, Experiment 2 was conducted to see if different stimulus-reinforcement patterns would produce differences in the discriminative and the reinforcing properties of the stimulus.

\section{Method}

Sixteen naive Ss, similar to those used in Experiment 1 , were initially trained in a manner identical to that of the first experiment and randomly divided into two equal groups $(\mathrm{N}=8)$. The 1 -sec houselight stimulus was presented on a variable schedule which averaged one presentation every $60 \mathrm{sec}$. Fifty stimulus presentations were given on each of Days 3 through 7 . Experiment 2 differed from Experiment 1 in that a barpress that followed the onset of the stimulus within $5 \mathrm{sec}$ was required for the delivery of reinforcement. In Group HT-SR, $10 \%$ of the reinforced stimulus presentations were followed by reinforced stimulus presentations, and $10 \%$ of the nonreinforced presentations were followed by nonreinforced presentations. The corresponding probabilities in Group LT-LR were $90 \%$ and $90 \%$. Response latency was defined as the duration of time between the onset of the stimulus and the next barpress. Response latencies following reinforced and nonreinforced stimulus presentations were recorded for both groups. On Day 8, the Ss were extinguished during a .5 h $\mathrm{h}$ session 
composed of 15 ABBA sequences of counterbalanced 30 -sec periods. A barpress during one 30-sec period produced the stimulus; a barpress during the other period did not.

\section{Results and Discussion}

Group HT-SR received an average of 22.3 N-R transitions per day, each following an $\mathrm{N}$-length that averaged 1.1 nonreinforcements. The corresponding averages in Group LT-LR were 2.6 and 10.1. The Day 7 mean latencies for each $S$ on trials following a reinforced stimulus presentation (post-SR latency) and on trials following a nonreinforced stimulus presentation (post-no-SR latency) provided the basic data. However, the within-cell variances were not homogeneous $\left(\mathrm{F}_{\mathrm{max}}=39.11, \mathrm{p}<.01\right)$; thus, the Mann-Whitney $U$ test and the Wilcoxon matched-pairs signed-ranks test ${ }^{2}$ (Siegel, 1956) were used in the data analysis. The mean post-SR and post-no-SR latencies of Group HT-SR were $1.52 \mathrm{sec}$ and $1.18 \mathrm{sec}$, respectively $(T=5, p<.05)$. The mean post-SR and post-no-SR latencies of Group LT-LR were $1.50 \mathrm{sec}$ and $3.36 \mathrm{sec}$, respectively $(T=1, p<.01)$. The significant differences between the post-SR and post-no-SR latencies for $S s$ in both groups indicated that each reinforcement schedule was discriminated. That is, Ss responded more quickly on trials with a $90 \%$ reinforcement probability than they did on trials with a $10 \%$ reinforcement probability. Thus, the presence or absence of reinforcement on a given trial became a discriminative stimulus that controlled behavior on the following trial. The post-SR latencies of the two groups were not significantly different $(U=32$, $\mathrm{p}>.50)$; however, the post-no-SR latencies were significantly shorter in Group HT-SR than in Group LT-LR ( $U=0, p<.001)$. The latencies for the two groups on trials with a $90 \%$ reinforcement probability (HT-SR post-no-SR and LT-LR post-SR) were not significantly different $(U=15$, p > .05); however, on trials with a $10 \%$ reinforcement probability (HT-SR post-SR and LT-LR post-no-SR), the Group HT-SR latencies were significantly shorter than the Group LT-LR latencies $(\mathrm{U}=1, \mathrm{p}<.001)$.

The mean number of extinction responses emitted during the stimulus period and during the no-stimulus period were 120.7 and 93.1, respectively $(\mathrm{F}=10.10, \mathrm{df}=1 / 14, \mathrm{p}<.01)$. This difference indicated that the stimulus had become a conditioned reinforcer $\left(\mathbf{S}^{\mathbf{r}}\right)$. That is, the stimulus increased resistance to extinction in both groups. The mean number of extinction responses emitted by Group HT-SR and by Group LT-LR were 96.0 and 117.8 , respectively $(F=1.19$, $\mathrm{df}=1 / 14, \mathrm{p}>.25)$. The Extinction Periods by Groups interaction was not significant $(F=1.02, \mathrm{df}=1 / 14, \mathrm{p}>.25)$, indicating that the pattern of reinforcement affected neither response strength nor $S^{r}$ strength. The latter finding is consistent with the results of Experiment 1.

The negative findings with respect to the effect of schedule pattern on $S^{\mathbf{r}}$ strength may be explained in three alternative ways. First, reinforcement pattern has no effect on $\mathbf{S}^{r}$ strength. Second, if both N-length and number of N-R transitions affect $S^{r}$ strength, the effects of one variable may have cancelled the effects of the other since high transition probability was associated with short $\mathrm{N}$-length, and vice versa. Third, Koteskey \& Stettner (1968) have suggested that the PRE effect is either absent or greatly reduced in situations where the reinforcement schedule is discriminated. The findings of the present study that reinforcement pattern had no effect on resistance to extinction supports this suggestion since the patterns were discriminated. The same explanation may apply to the negative finding with respect to $\mathbf{S}^{\mathbf{r}}$ strength. Research that eliminates pattern discrimination by the use of less extreme transition probabilities and which does not confound $\mathrm{N}$-length and number of $\mathrm{N}-\mathrm{R}$ transitions is indicated.

\section{REFERENCES}

AMSEL, A. The role of frustrative nonreward in noncontinuous reward situations. Psychological Bulletin, 1958, 55, 102-119.

CAPALDI, E. J. Effect of N-length, number of different N-lengths and number of reinforcements on resistance to extinction.
Journal of Experimental Psychology, 1964, 68, 230-239.

CAPALDI, E. J., \& STANLEY, L. R. Percentage of reward vs $\mathrm{N}$-length in the runway. Psychonomic Science, 1965, 3, 263-264.

GONZALEZ, R. C., \& BITTERMAN, M. E. Resistance to extinction in the rat as a function of percentage and distribution of reinforcement. Journal of Comparative \& Physiological Psychology, 1964, 58, 258-263.

KIMBLE, G. A. Hilgard and Marquis' conditioning and learning. New York: Appleton-Century-Crofts, 1961.

KOTESKEY, $R$. L. The effect of unreinforced-reinforced sequences on resistance to extinction following partial reinforcement. Psychonomic Science, 1969, $14,34 \& 36$.

KOTESKEY, R. L., \& STETTNER, L. J. Role of nonreinforcement-reinforcement sequences in the partial reinforcement effect. Journal of Experimental Psychology, 1968, 76, 198-205.

LAWRENCE, D. H., \& FESTINGER, L. Deterrents and reinforcement. Stanford: Stanford University Press, 1962.

MOWRER, O. H., \& JONES, H. Habit strength as a function of the pattern of reinforcement. Journal of Experimental Psychology, 1945, 35, 293-311.

SIEGEL, S. Nonparametric statistics. New York: McGraw-Hill, 1956.

SPIVEY, J. E., \& HESS, D. T. Effect of partial reinforcement trial sequences on extinction performance. Psychonomic Science, 1968, 10, 375-376.

SPIVEY, J. E., HESS, D. T., \& BLACK, D. Influence of partial reinforcement pattern and intertrial reinforcement on extinction performance following abbreviated training. Psychonomic Science, 1968, 10, 377-378. NOTES

1. The author thanks John C. Birkimer for his comments on this manuscript.

2. Significance levels for the Wilcoxon signed-ranks tests are one-tailed.

\section{Effect of CS position reversal on extinction in shuttle air-blast avoidance}

\author{
THOMAS W. BAKER and DONALD \\ ZIEGELBAUER, Lawrence University, \\ Appleton, Wis. 54911
}

Squirrel monkeys were trained to avoid an airblast in a two-way shuttle procedure. Following acquisition and after a 10-day rest, one group received 5 days of relearning, the other group received 2 days of relearning and 3 days of training with CS position reversed. Both groups were then extinguished to the $C S$ in its original position. The reversed group exhibited significantly greater resistance to extinction.
Recently, Polidora \& Boyer (1967) reported rapid and stable avoidance learning by squirrel monkeys using an airblast US. These findings were similar to those reported for rats (Ray, 1966a, b) and for cats (Ray, 1966c). McAdam (1964), using cats as Ss, found that avoidance learning was slower if the task required the $S$ to shuttle toward the CS rather than away from it. Whittleton, Kostanek, \& Sawrey (1965) extended these findings using rats as Ss and, in addition, showed that extinction was more rapid under the condition that required the $S$ to shuttle toward the CS. The present study attempted to assess the effects of a change 